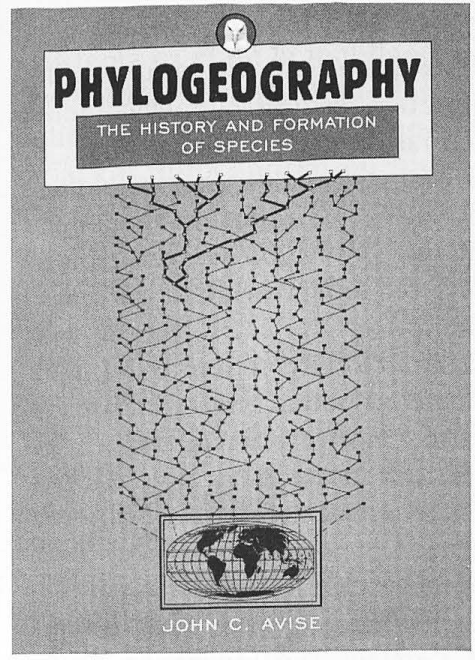

F ilogeografía es un término nuevo, propuesto en 1987 por John Avise para referirse a las congruencias que muchas veces se observan entre las filogenias moleculares y la distribución geográfica de los individuos analizados. Desde los primeros estudios que se realizaron analizando mitocondrias en vertebrados, se encontró diferenciación geográfica. Estos datos, aunados a la facilidad para estudiar el genoma mitocondrial en animales, han provocado una auténtica revolución, con cientos de trabajos que estudian estos patrones en vertebrados y otros animales. En este libro, Avise revisa parte de esta novedosa y extensa literatura y la compara y organiza a partir de una revisión de sus bases teóricas y los patrones que se detectan.

La filogeografía se podría entender como una subdisciplina de la evolución, en la cual se hacen inferencias evolutivas dentro de una especie a partir de información molecular, pero que paradójicamente casi no utiliza a la teoría de la genética de poblaciones. Usualmente, estos análisis se basan en datos de ADN de la mitocondria, ya sea derivados de RFLPs, o más recientemente, directamente de sus secuencias, principalmente de

\section{Phylogeography: The History and Formation of Species}

\author{
JOHN C. AVISE \\ Harvard University Press. 2000. Cambridge, Massachusetts. \\ 447 pags. ISBN 0-674-66638-0
}

un par de genes (la "región controladora" y el citocromo b). Las razones de esto son sencillas. Las mitocondrias de animales tienen un genoma propio, que está muy conservado estructuralmente (casi siempre tiene los mismos genes en el mismo orden), constituyen un genoma muy abundante y corto, y por lo tanto se puede aislar fácilmente, y se han diseñado una serie de primers "universales" para PCR, que permiten estudiarlas en cualquier tipo de animal. Otras ventajas de las mitocondrias es que se heredan maternamente, y que no tiene recombinación, por lo que es mucho más fácil analizarlas que los genes nucleares, que siempre presentan recombinación y tienen tamaños efectivos mayores, al heredarse biparentalmente.

Sorprendentemente, en las más de 1200 referencias del libro, sólo 27 tratan de manera más o menos directa a las plantas. Considero que esto se debe a tres razones principales. La primera y tal vez la más importante, es que en plantas no tenemos un marcador tan fácil de usar y tan variable como las mitocondrias de los animales. Las plantas obviamente tienen mitocondrias, pero sus secuencias cambian muy despacio, por lo que casi no se encuentran diferencias a nivel ADN aún comparando especies de grupos muy diferentes. Los cloroplastos también tienen genoma, pero igual que las mitocondrias cambian lentamente, y por ejemplo, la mayoría de sus genes son idénticos entre géneros dentro de una familia. Los genes nucleares en plantas parecen ser nuestra única opción, pero estos tiene dinámicas más complejas y resultan mucho más difíciles de estudiar. Otra razón es que el estudio de la biología evolutiva (y molecular) en plantas siempre ha estado más atrasado que en animales. El atraso es considerable, e informalmente se maneja que es de unos diez años. Técnicas, idea y métodos que se exploraron y publicaron hace 10 años en estudios con animales y humanos, apenas se comienzan a aplicar en plantas. La última razón es que Avise es un especialista en vertebrados, y es normal que no maneje la literatura de las plantas (aunque tampoco parece haber hecho ningún esfuerzo). En revistas como Molecular Ecology en cada número se publican artículos que pudieran ubicarse dentro de esta subdisciplina, pero ciertamente son mucho menos que los realizados en animales. 
Los análisis que se publican dentro de la filogeografía suenan brillantes y convincentes, inicialmente. Sin embargo, cuando revisamos críticamente cada uno de los trabajos, las dudas surgen: ¿no será solamente que a partir de una reconstrucción filogenética han inventado una bonita historia evolutiva? ¿Qué tan adecuados son los muestreos (que usualmente sólo abarcan unas decenas de organismos, muchas veces de sólo algunas poblaciones dentro de todo el rango de distribución de la especie)? ¿Qué tan confiables son estas filogenias? ¿No cambiarían estas filogenias con más individuos, poblaciones, secuencias (caracteres) o con otros métodos de reconstrucción filogenética? Avise da poco espacio para meditar sobre estas dudas. De las decenas de filogenias que ilustra, rara vez menciona las distancias genéticas o métodos que usaron para reconstruirlas, ni menciona la confiabilidad (como valores de bootstrap) en las bifurcaciones que presentan. Otra duda que surge sobre esta metodología es la falta de análisis de genética de poblaciones, ya que las interpretaciones generalmente sólo se basan en la forma de la filogenia. Rara vez discuten niveles de variación genética entre ni dentro poblaciones, o mencionan análisis a nivel poblacional. Por otra parte, dado que no tiene recombinación, el genoma entero de la mitocondria se comporte como un solo gen de los miles que posee un individuo de cada especie, y su filogenia tal vez nos hable de parte de la historia de la especie, pero las filogenias, tiempos de coalescencia, etc. de todos los otros genes podrían ser muy diferentes, especialmente si las hembras de dicha especie se dispersan diferente que los machos (como sucede en muchas especies de vertebrados).

Sin embargo, debemos reconocer que el libro está muy bien es- crito y Avise es indudablemente una de las personas mejor calificadas en el mundo para hablar sobre el tema. El libro es claro e interesante, y las ilustraciones son abundantes y de gran calidad, lo mismo que la tipografía y el formato. Veamos brevemente cada capítulo.

El primer capítulo trata sobre la historia y la relevancia de la filogeografía. Yo consideraría a la filogeografía como parte de la genética de poblaciones, pero Avise claramente piensa que tiene un papel mucho más importante, considerándola una rama independiente de la biología evolutiva que constituye el puente ente la micro- y la macro- evolución. El capítulo describe el sorprendente descubrimiento a mediados de los años setentas de que los genes de las mitocondrias en animales cambian mucho más rápido que los genes que se encuentran en el núcleo, y que por lo tanto podían funcionar para estudios intraespecíficos. Las ventajas en términos de claridad y sencillez de interpretación de estos datos sobre los patrones que mostraban las alozimas fueron claros desde el principio. En las alozimas, la mayor parte de las poblaciones comparten alelos, y las diferencias deben analizarse estadísticamente, mientras que las mitocondrias, al tener tamaños efectivos menores (ya que sólo se trasmiten por vía materna) y cambiar muy rápidamente, permitían detectar diferentes tipos de secuencias entre individuos de una población, y las diferencias entre poblaciones en las reconstrucciones filogenéticas se detectaban mucho más fácilmente.

El capítulo dos es una revisión de diferentes aspectos teóricos que ayudan a explicar por qué (a veces) se pueden detectar patrones filogeográficos, analizando pocos individuos de cada población. El capítulo se basa en simulaciones que Avise publicó previamente, en las que analiza procesos demográficos dentro de un contexto filogenético, estudios genéricamente llamados de "coalescencia". El tiempo a la coalescencia es el tiempo en el que todas las secuencias de una población se derivaron de una secuencia original (o sea, el tiempo en el cual se pierde toda la variación) y depende del tamaño de las poblaciones y la distribución (media y varianza) de las fecundidades en la poblaciones. Datos mitocondriales de diferenciación para algunas especies abundantes y una aproximación al reloj molecular, sugieren que los tamaños efectivos evolutivos son mucho menores que los observados actualmente. Así, se justificaría que se utilicen tamaños de muestra pequeños en estos estudios, debido a la baja variación dentro de las poblaciones. Avise describe los patrones de filogenias que se pueden obtener en diferentes circunstancias (desde que cada población tenga solamente secuencias pertenecientes a clados independientes en su filogenia, a que se compartan muchas o todas las secuencias en todas las poblaciones). Por último compara sus incipientes métodos filogeográficos con métodos de genética de poblaciones para estimar flujo génico (como derivar Nm a partir de Fst, de alelos raros, o de incongruencias en las filogenias), para concluir el capítulo con una revisión de la posibilidad de aplicar con éxito las ideas sobre filogeografía usando genes nucleares.

Creo que el reto más importante de la filogeografía es precisamente éste, entender por qué, cómo y cuándo funciona y enmarcarla claramente dentro de la teoría general de la genética de poblaciones.

Todos los capítulos restantes tratan de la descripción de patrones detectados en los estudios filogeográficos. El capítulo tres trata temas relacionados con estudios 
mitocondriales en humanos. El primer tema es el de la mal llamada "Eva mitocondrial". Desde los estudios inciales, se detectó que la variación mitocondrial en humanos era muy baja, lo indica tiempos de origen (de coalescencia) muy cercanos, de entre 180 a 360 mil años. Eso quiere decir que todas las mitocondrias que tenemos los humanos se derivaron de una sola mitocondria, en una sola mujer que vivió hace relativamente pocas generaciones. Esta idea, mal entendida por los medios de comunicación, sugería que esa mujer era la primera mujer, o sea Eva.

Esto es falso, ya que nuestra especie surgió mucho antes, y la población total era de varios miles de personas (mas de $10 \mathrm{mil}$ ), y de una de ellas, por puro azar se derivan todas las mitocondrias actuales, pero todos los otros genes tendrían otros tiempos de coalescencia. Posteriormente, el grupo de Allan Willson analizó a más personas y sugirió que la raíz de la filogenia estaba en África, al presentar la mayor diversidad de haplotipos y aparentemente a los haplotipos más primitivos (aunque este resultado depende fuertemente de los métodos usados para enraizar el árbol). Estudios utilizando genes nucleares, en particular del cromosoma Y (que sólo se hereda por vía paterna, y daría una especie de Adán, pero desafortunadamente sus genes son poco variables) dan patrones similares, apoyando la idea de un origen africano y tamaños poblacionales de miles de individuos. El resto del capítulo describe otros estudios, como la colonización original de América, y de las islas del Pacífico, algunos sobre dispersión (que indican que la migración mediada por mujeres es varios veces superior a la migración por hombres) y los poco datos moleculares que se han obtenido sobre el hombre de Neanderthal. El capítulo es in- teresante, pero es frustante, ya que los humanos son un mal ejemplo para discutir patrones filogeográficos, porque tienen muy poca variación y diferenciación geográfica, y la mayor parte de las poblaciones comparten la mayoría de los alelos.

Los patrones intraespecíficos para todos los otros animales se tratan en el siguiente capítulo. Éste inicia con la propuesta de cinco categorías filogeográficas, que van de la categoría I, donde la filogenia refleja a la geografía y se detecta una clara diferenciación regional (en cada localidad sólo se encuentran unas secuencias, relacionadas entre sí y diferentes de todas las demás), hasta la Categoría $\mathrm{V}$, donde no hay diferenciación geográfica, y todas las secuencias son muy parecidas y se comparten entre poblaciones. Empleando estas categorías como marco de referencia, revisa estudios realizados en diferentes grupos de animales. Inicia con los mamíferos, y los "pequeños y terrestres" se portan muy bien ya que en muchas especies se detectan patrones geográficos muy claros (debidos indudablemente a sus limitadas capacidades de dispersión). Las excepciones son usualmente especies con distribución muy local, donde a veces no se detecta diferenciación. En otros mamíferos (como los terrestres más grandes, en los acuáticos y en los voladores) no siempre se encuentran ajustes filogeográficos claros, aunque es difícil predecir en cuáles especies se va encontrar diferenciación. Posteriormente revisa numerosos estudios en los otros grupos de vertebrados y algunos grupos de invertebrados, y los patrones son análogos: en algunas especies es encuentra fuerte diferenciación geográfica, usualmente en las menos móviles.

El capítulo cinco trata sobre la "concordancia genealógica". La idea es sencilla: si los patrones que detectan en sus filogenias son robustos y confiables van a ser útiles para entender la evolución y biogeografía. Así,propone cuatro "aspectos" de congruencia: el primero es que las filogenias sean buenas (con un buen soporte estadístico de los grupos, dados por altos valores de bootstrap), el segundo es que diferentes genes den la misma filogenia, el tercero es que varias especies tengan patrones filogeográficos similares, y el cuarto es que los patrones filogeográficos sean congruentes con las provincias biogeográficas tradicionalmente descritas. En general, su visión y descripción de estos "aspectos" me parece poco formal, demasiado cualitativa y primitiva, en particular en relación al cuarto aspecto, y ciertamente, no usa estas ideas en la discusión de los patrones descritos en el capítulo anterior. Describe con detalle el caso de los vertebrados del sureste de los Estados Unidos, generalmente considerado el mayor éxito de la filogeografía: en muchas especies de peces de agua dulce, en animales marinos, y en tortugas de agua dulce y terrestres, se ha encontrado una muy clara diferenciación genética entre las poblaciones de la costa este, y las del Golfo de México, siendo Florida el parteaguas. Esta diferenciación se puede explicar en términos históricos y es congruente con los patrones biogeográficas a nivel de especie tradicionalmente descritos. Otros buenos ejemplos de congruencia entre la biogeografía y la filogeografía los dan algunos los mamíferos pequeños de la selva del Amazonas, que muestran una clara diferencia entre las poblaciones en alto Amazonas (en Perú) con las del bajo Amazonas (en Brasil). A continuación menciona el único ejemplo que detalla en plantas, el estudio usando RFLPs de cloroplasto en seis especies de la costa Oeste de los Estados Unidos. En estas espe- 
cies Douglas y Pamela Soltis han encontrado una clara diferenciación entre las poblaciones del Norte, en el estado de Washington y Canadá, y las del Sur de California, detectando poblaciones mezcladas alrededor del estado del Oregon. Otros ejemplos que detalla son sobre la diferenciación surgida antes de que se abriera el estrecho de Bering y cuando se formó Panamá, usando datos de peces e invertebrados, y el caso de Hawaii, usando aves y drosofilas. Todos estos últimos casos tienen en común que los eventos geológicos que dieron origen a las poblaciones se pueden fechar con relativa confiabilidad. Para concluir el capítulo, discute la relevancia de los patrones filogeográficos para la biología de la conservación (en otras palabras, como definir las "unidades evolutivamente significativas"), y cuando se originaron la mayoría de las poblaciones (llamadas filogrupos en este contexto) en los grupos de vertebrados, a partir de la diferenciación y relojes moleculares Aparentemente, la mayoría se originó en el Pleistoceno, pero este análisis depende de las tasas de evolución y los tiempos de calibración, para lo cual hay pocos datos confiables.

El último capítulo se llama "Procesos de especiación y genealogía extendida", y es un intento de ampliar sus ideas más allá de las especies. El primer paso es entender las relaciones entre las genealogías (árboles de genes) y la filogenia real de las especies, ya que el árbol de un gene no necesariamente refleja la evolución de toda una especie porque se pueden compartir alelos entre especies. Con estas ideas en mente, revisa diferentes conceptos y definiciones (en particular el concepto biológico versus el concepto filogenético de especie) para tratar de entender más claramente qué son las especies. A continuación, siguiendo con lo sugerido en el capítulo anterior, revisan los tiempos de origen de las especies de vertebrados, sugiriendo orígenes para la mayoría, de hace menos de dos millones de años. Luego discute el análisis de filogenias profundas, e ilustra estas ideas con análisis que se han podido hacer con algunos grupos de animales, como peces que se encuentran en África y América del Sur que datan de antes de la separación de ambos continentes y en los cuales se de- tectan claras relaciones entre las filogenias y la distribución geográfica. El libro concluye con una breve presentación de las ideas sobre mapeo de caracteres en filogenias y en la geografía.

En conclusión, es un libro actualizando, interesante y enciclopédico (por ejemplo, ; tiene 96 páginas de referencias!), y es una lectura importante para todos los biólogos interesados en evolución a nivel intraespecífico. Conozco varias tesis de doctorado trabajando con plantas que incluyen la palabra filogeografía en su título, una clara señal de que éste va a ser un campo de estudio de moda en los príximos años. Sólo el tiempo nos dará los datos y la perspectiva para evaluar si Avise tiene razón en que la filogeografía realmente es una disciplina independiente dentro de la biología, o sólo es una forma de ver a la genética de poblaciones y a la evolución molecular.

\section{Luis E. Eguiarte}

Instituto de Ecología, Universidad Nacional Autónoma de México 